\title{
Numerical Investigation of Temperature Distribution in an Eroded Bend Pipe and Prediction of Erosion Reduced Thickness
}

\author{
Hongjun Zhu, ${ }^{1}$ Guang Feng, ${ }^{2}$ and Qijun Wang' \\ ${ }^{1}$ State Key Laboratory of Oil and Gas Reservoir Geology and Exploitation, Southwest Petroleum University, \\ Chengdu, Sichuan 610500, China \\ ${ }^{2}$ CNPC Key Laboratory for Tubular Goods Engineering, Southwest Petroleum University, Chengdu, Sichuan 610500, China
}

Correspondence should be addressed to Hongjun Zhu; ticky863@126.com

Received 9 September 2013; Accepted 12 January 2014; Published 24 February 2014

Academic Editors: G. Milani and A. Szekrenyes

Copyright (C) 2014 Hongjun Zhu et al. This is an open access article distributed under the Creative Commons Attribution License, which permits unrestricted use, distribution, and reproduction in any medium, provided the original work is properly cited.

\begin{abstract}
Accurate prediction of erosion thickness is essential for pipe engineering. The objective of the present paper is to study the temperature distribution in an eroded bend pipe and find a new method to predict the erosion reduced thickness. Computational fluid dynamic (CFD) simulations with FLUENT software are carried out to investigate the temperature field. And effects of oil inlet rate, oil inlet temperature, and erosion reduced thickness are examined. The presence of erosion pit brings about the obvious fluctuation of temperature drop along the extrados of bend. And the minimum temperature drop presents at the most severe erosion point. Small inlet temperature or large inlet velocity can lead to small temperature drop, while shallow erosion pit causes great temperature drop. The dimensionless minimum temperature drop is analyzed and the fitting formula is obtained. Using the formula we can calculate the erosion reduced thickness, which is only needed to monitor the outer surface temperature of bend pipe. This new method can provide useful guidance for pipeline monitoring and replacement.
\end{abstract}

\section{Introduction}

Erosion wear is a prominent issue for pipelines conveying fluid, which usually cause significant operation and reliability problems in oil and gas, coal, slurry, aerospace, pneumatic conveying, and other industries $[1,2]$. As an integral part of piping systems, elbows are known to be responsible for dramatic change in flow field, high pressure loss, and secondary flow, which are vulnerable in erosive environments. Therefore, erosion in elbows has been experimentally or numerically analyzed by many investigators [3-6]. And several empirical or semiempirical correlations have been developed to predict erosion in elbows. However, the erosion phenomenon is highly complicated due to plenty of parameters affecting the erosion severity, such as flow rate, fluid properties, pipe material, and pipe geometry. These correlations, thus, are limited to special working conditions as stated in the studies, which cannot be used for all erosion predictions.

After pipe is put into use, erosion in elbow has been happening all the time, resulting in mass loss from the inner wall of pipe, wall thinning, and even break. The timely replacement of elbow before its failure is very important. However, we do not know the erosion reduced thickness of pipe and when the pipe would damage. Thus, a quick and easy method is urgently needed to predict the erosion reduced thickness.

A number of fluids are heated before conveying, such as hot oil, hot water, and some chemical fluids. There is a temperature difference between inside and outside of the pipe, and heat transfer inevitably occurs. Due to wall thinning, the heat flux in the eroded site is different from the rest of the pipe. Therefore, the temperature distribution in an eroded bent pipe may provide some useful information for us to calculate the erosion. Unfortunately, few works of literature have studied erosion from the perspective of temperature distribution.

In order to find a new method to predict the erosion reduced thickness, the temperature distribution in an eroded bend pipe for conveying hot oil flow has been investigated. Since numerical simulation can provide detailed information on temperature field and has advantages of low cost and short 


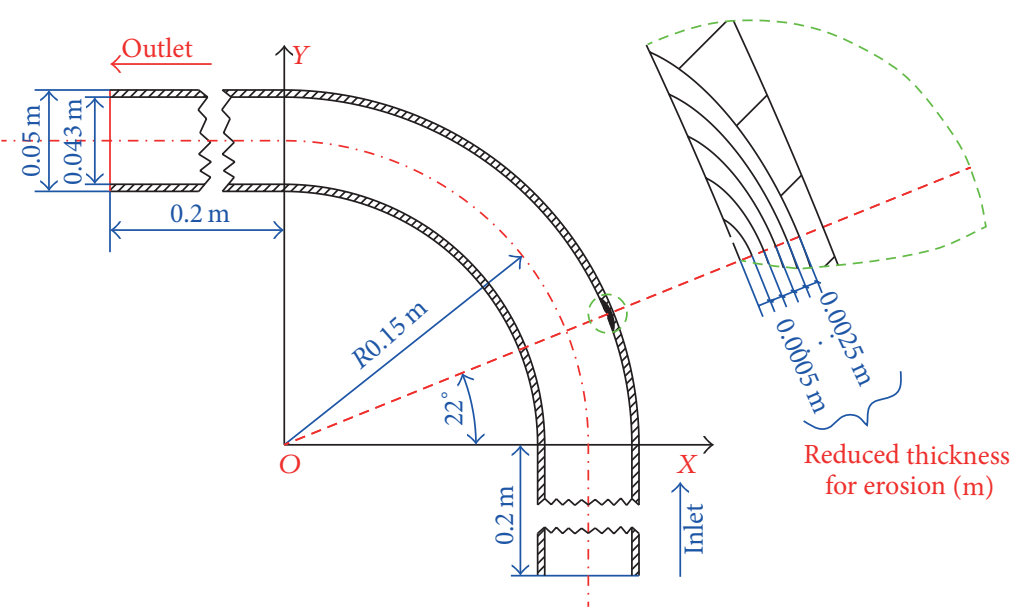

(a)

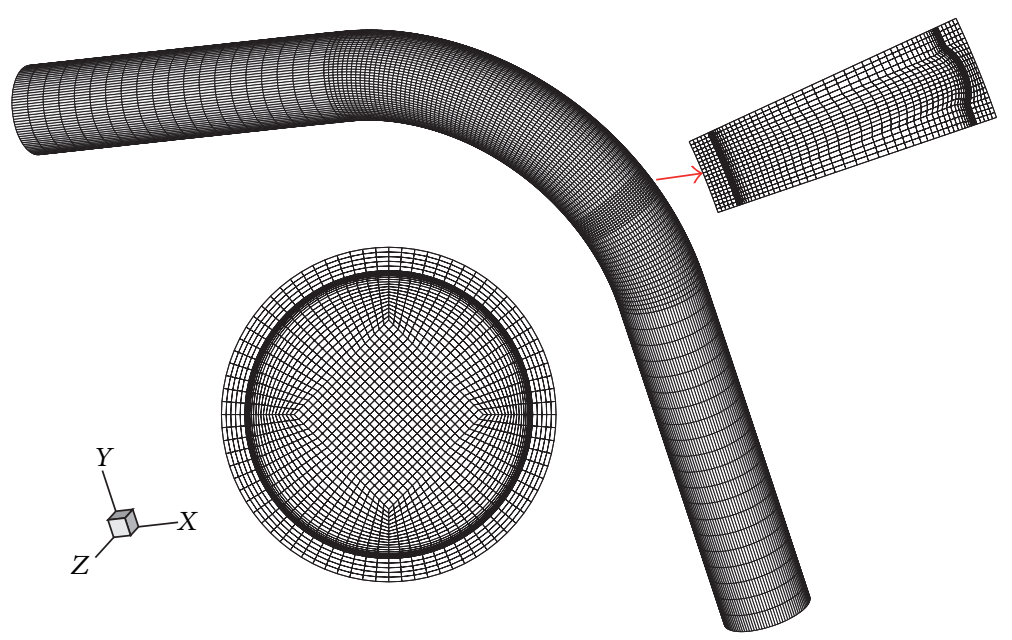

(b)

FIGURE 1: Sketch of the geometry and numerical grid for computational domain: (a) overall view of the computational domain and boundary conditions; (b) grid distribution of computational domain.

research time, in present work, computational fluid dynamics (CFD) model has been employed to explore the temperature distribution in an eroded pipe. By conducting a series of numerical simulations, effects of inlet temperature of oil flow, inlet flow rate, and erosion reduced thickness are examined. Then, the dimensionless minimum temperature drop is analyzed and the fitting formula is obtained. Using the formula we can calculate the erosion reduced thickness, which is only needed to monitor the outer surface temperature of bend pipe. Using the method of fitting formula is shown in this paper by examples.

The remaining part of this paper is organized as follows. In Section 2, the description of simulation method is provided; Section 3 presents the numerical results and discussion; Section 4 presents the concluding remarks.

\section{Simulation Method}

2.1. Governing Equations. As incompressible fluid, the oil flow is governed by the universal averaged Navier-Stokes equations, including the conservation of mass, momentum, and energy, taking the following form $[7,8]$ :

$$
\begin{gathered}
\nabla \cdot \vec{v}=0 \\
\frac{\partial \vec{v}}{\partial t}+\nabla \cdot(\vec{v} \vec{v})=-\frac{1}{\rho} \nabla p+\vec{g}+\frac{1}{\rho} \nabla \cdot \vec{\tau} \\
\frac{\partial e}{\partial t}+\nabla \cdot(\vec{v} e)=-\frac{p}{\rho} \nabla \cdot \vec{v}+\Phi+\frac{1}{\rho} \frac{\partial}{\partial x_{i}}\left(\lambda \frac{\partial T}{\partial x_{i}}\right)+q_{R}
\end{gathered}
$$

where $v$ represents flow rate, $t$ is time, $\rho$ is oil density, $g$ is gravitational acceleration, $p$ is pressure, $\tau$ is viscous stress, $e$ is per unit mass of internal energy, $\Phi$ is per unit mass of energy dissipation by viscous friction, $x_{i}$ is space coordinate in $i$ direction, $T$ is temperature, and $\lambda$ and $q_{R}$ are coefficient of heat conductivity and per unit mass of radiant heat transfer rate, respectively.

The heat transfer is composed of three components, namely, the convective heat transfer between the flowing oil and the inner wall of the pipe, the heat conduction in steel 

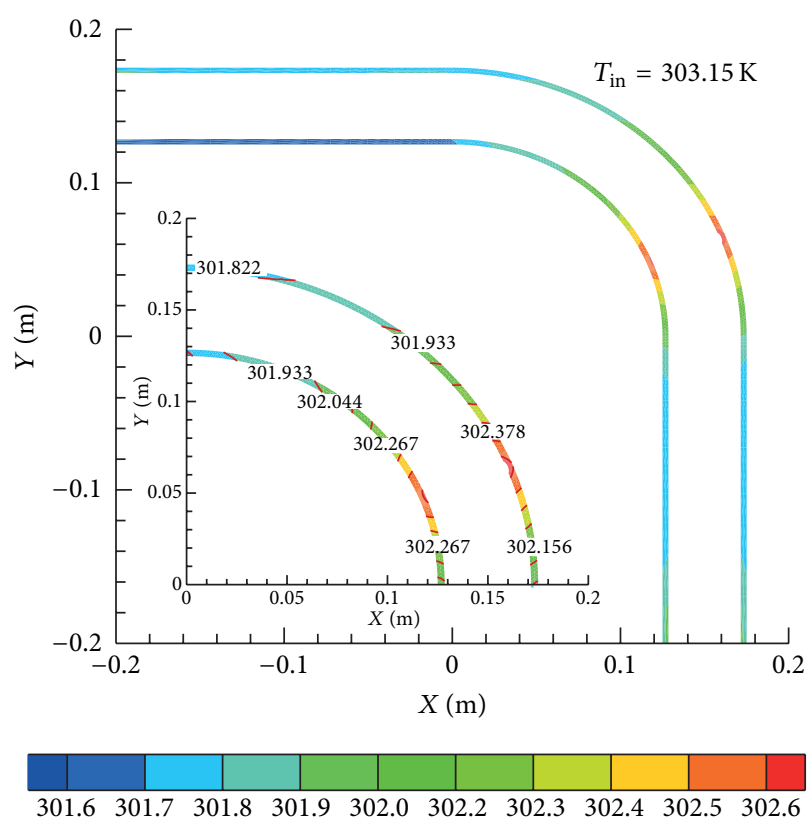

(a)
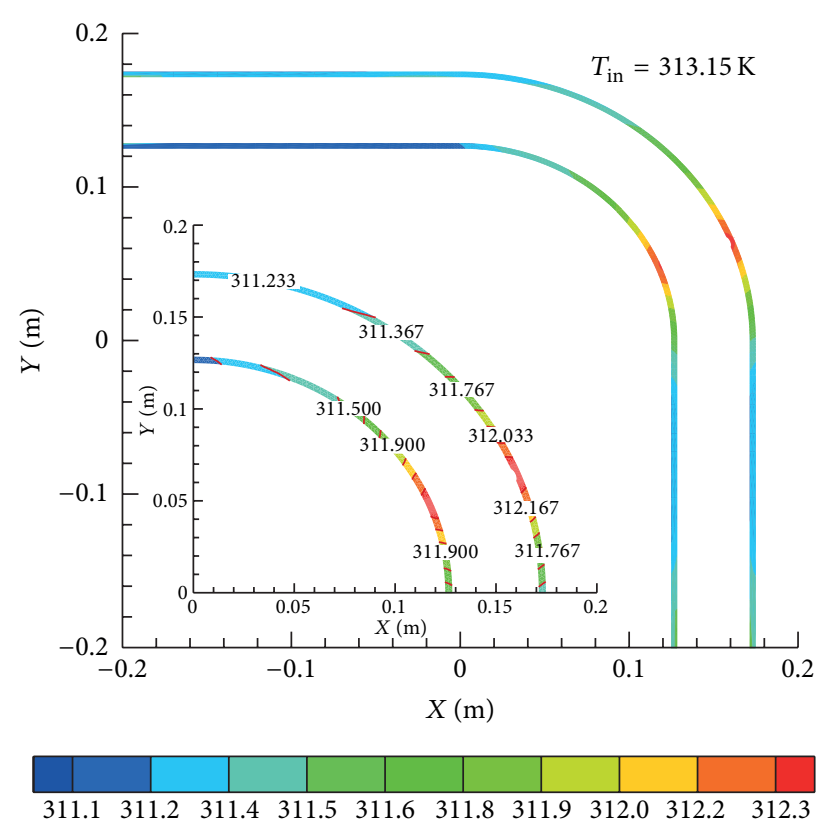

(b)
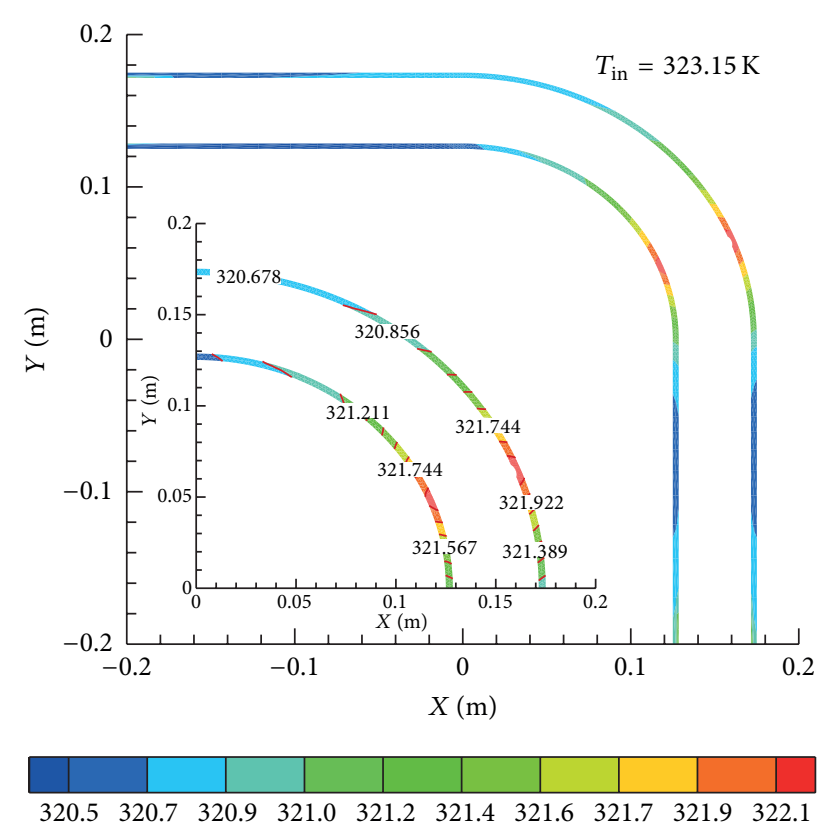

(c)

FIGURE 2: Temperature distribution at the longitudinal cross section of bend pipe at different inlet temperatures.

pipe, and the convective heat transfer between the outer wall of the pipe and air. The radial heat flux per unit length is the same in the heat transfer process, written as

$$
q=h_{\mathrm{i}} \pi d_{\mathrm{i}}\left(T-T_{\mathrm{i}}\right)=\frac{2 \pi \lambda_{\mathrm{p}}\left(T_{\mathrm{i}}-T_{\mathrm{o}}\right)}{\ln \left(d_{\mathrm{o}} / d_{\mathrm{i}}\right)}=h_{\mathrm{o}} \pi d_{\mathrm{o}}\left(T_{\mathrm{o}}-T_{\mathrm{a}}\right),
$$

where subscripts $i$ and o represent "inner" and "outer," respectively, $h$ is convection heat transfer coefficient, $d$ is diameter, $\lambda_{\mathrm{p}}$ is heat conductivity coefficient of pipe, and $T_{\mathrm{a}}$ is the air temperature outside the pipe.

In this study, Reynolds number ranges from 746.05 to 1492.1. So laminar flow model is employed.

2.2. Numerical Method. Finite volume method is employed to discretize the above equations. All the calculations are conducted using a commercial software package FLUENT 14.5. Patankar's well-known SIMPLE algorithm [9] is employed to solve the pressure-velocity coupling. And 
TABLE 1: Physical characteristics of materials used in simulation.

\begin{tabular}{lcccc}
\hline Item & Density $\left(\mathrm{kg} \cdot \mathrm{m}^{-3}\right)$ & $\begin{array}{c}\text { Specific heat capacity } \\
\left(\mathrm{KJ} \cdot \mathrm{kg}^{-1} \cdot \mathrm{K}^{-1}\right)\end{array}$ & $\begin{array}{c}\text { Coefficient of heat } \\
\text { conductivity }\left(\mathrm{W} \cdot \mathrm{m}^{-1} \cdot \mathrm{K}^{-1}\right)\end{array}$ & $\begin{array}{c}\text { Kinetic viscosity } \\
(\mathrm{Pa} \cdot \mathrm{s})\end{array}$ \\
\hline Crude oil & 867.5 & 1.8 & $0.61-0.01187 T$ & 0.05 \\
Steel pipe & 8030 & 0.502 & 16.27 & \\
\hline
\end{tabular}

second-order upwind scheme and second-order centraldifferencing scheme are applied for convective terms and diffusion terms, respectively, in order to ensure the accuracy of calculation. The convergent criteria for all calculations are set such that the residual in the control volume for each equation is smaller than $10^{-6}$.

2.3. Computational Domain and Mesh. Figure 1 shows a sketch of the geometry and numerical grid for computational domain investigated in this study. The eroded bend pipe is placed horizontally, consisting of three parts: front straight pipe section, bend section, and rear straight pipe section. The lengths of front straight pipe and rear straight pipe are both $0.2 \mathrm{~m}$. The inner and outer diameters of bend pipe are $0.043 \mathrm{~m}$ and $0.05 \mathrm{~m}$, respectively. The curvature and diameter ratio of the elbow $\left(R / d_{\mathrm{o}}\right)$ is set to 3 ; namely, the curvature radius is $0.15 \mathrm{~m}$. Since $20-35^{\circ}$ along the extrados of bend is the most severe erosion area $[10,11]$, the eroded pit in this study is located $22^{\circ}$ downstream the inlet of bend. And the pit is semiellipsoidal with the maximum depth ranging from $0.5 \mathrm{~mm}$ to $2.5 \mathrm{~mm}$, in order to compare the difference of temperature distribution at different erosion reduced thicknesses.

ICEM CFD mesh generator is employed to perform the geometry generation and meshing. As shown in Figure 1, the computational domain along the pipe axial direction is divided into five blocks and progressive mesh is used. The densest grids present in the vicinity of erosion pit. In the cross section, the fluid computational domain is also divided into five blocks, and a boundary layer is set near the pipe wall with four-layer grids (the cell height of the first layer is $0.05 \mathrm{~mm}$ and the growth factor is 1.2) to capture the near-wall flow properties, while the grids in pipe (solid computational domain) show uniform distribution. The pipe is divided into five grids along the radial direction, and the number is unchanged even in the thinnest wall. In order to control the grid distribution and computational stability, the whole domain is discretized with hexahedral cells. A suitable grid density is reached by repeating computations until a satisfactory independent grid is found. At last, the number of grid cells used in calculation is $2.7 \times 10^{5}$.

2.4. Boundary Conditions. Uniform velocity is taken as the inlet condition in this work. After passing through the front straight pipe ( $L=4 d_{\mathrm{o}}$ ), it will form a fully developed flow. In order to examine the effect of inlet rate, the oil velocity is taken as $1 \mathrm{~m} / \mathrm{s}, 1.5 \mathrm{~m} / \mathrm{s}$, or $2 \mathrm{~m} / \mathrm{s}$ in comparing the cases. The inlet temperature of oil flow is also defined in the entrance, which is set to $303.15 \mathrm{~K}, 313.15 \mathrm{~K}$, and $323.15 \mathrm{~K}$ to observe the effect of oil flow temperature.

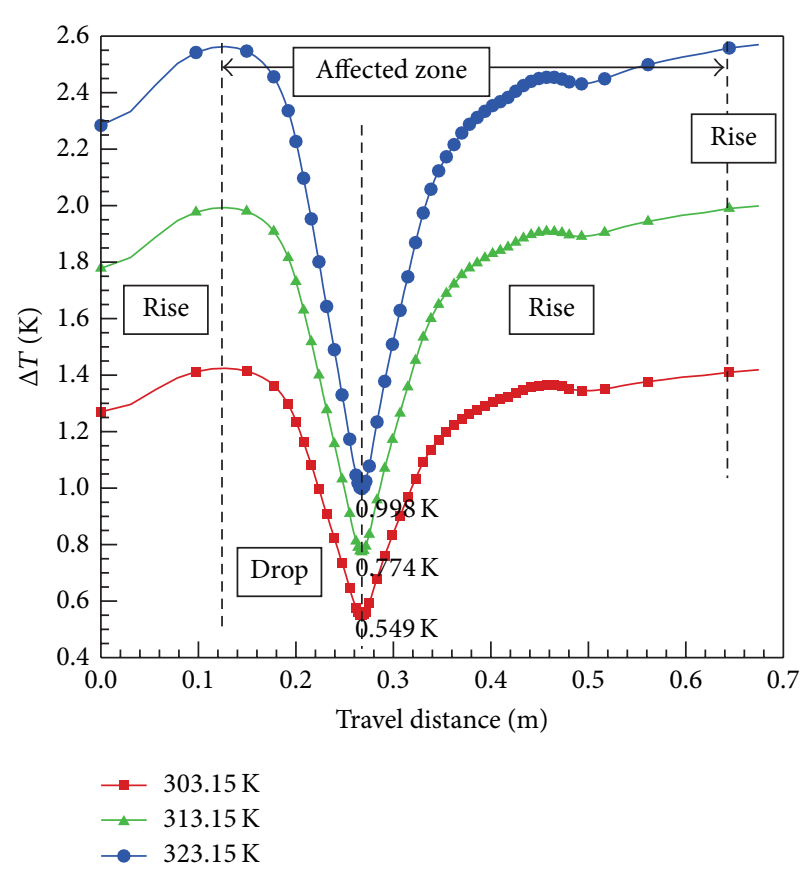

FIGURE 3: Effect of inlet temperature on temperature drop along the extrados of pipe.

A free outflow boundary condition is used in the outlet, which means that the value in outlet is obtained by calculating the flow field from the upstream. No slip boundary condition is imposed on the pipe wall. At the inner wall of bend pipe, convective heat transfer between oil and pipe wall and heat conduction in steel pipe are coupled. And at the outer wall of bend pipe, heat conduction in steel pipe and convective heat transfer between air and pipe wall are coupled. The air temperature outside the pipe is fixed at $278.15 \mathrm{~K}$ in all cases. And the convection heat transfer coefficient outside the pipe is defined as $5 \mathrm{~W} /(\mathrm{m} \cdot \mathrm{K})$.

The physical characteristics of materials used in simulation are listed in Table 1 . Nine cases are simulated to compare the different influences among different inlet rates, inlet temperatures, and erosion reduced thicknesses, as listed in Table 2.

\section{Numerical Results and Discussion}

3.1. Effect of Inlet Temperature. Oil is usually heated to different temperatures according to the actual working condition before it enters the pipeline. We adopt case 1 (as shown in Table 2) as the standard case. In this section, to study the effect of oil inlet temperature $\left(T_{\text {in }}\right)$, simulations are 


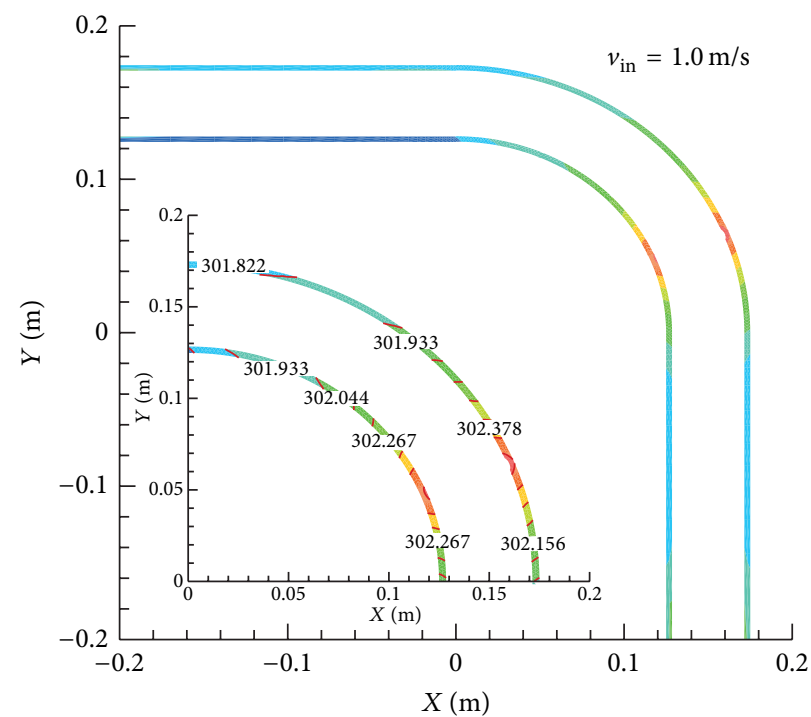

(a)

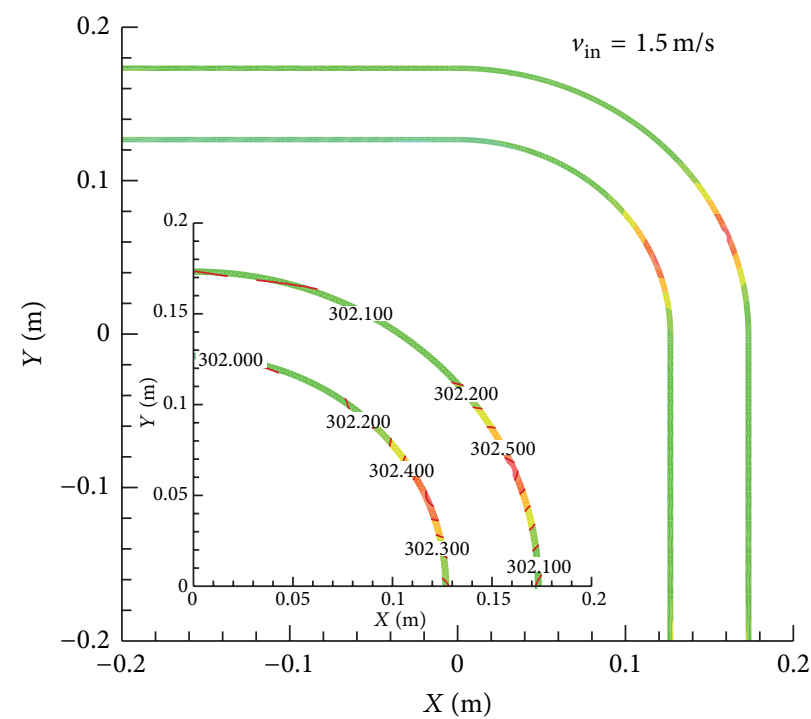

(b)
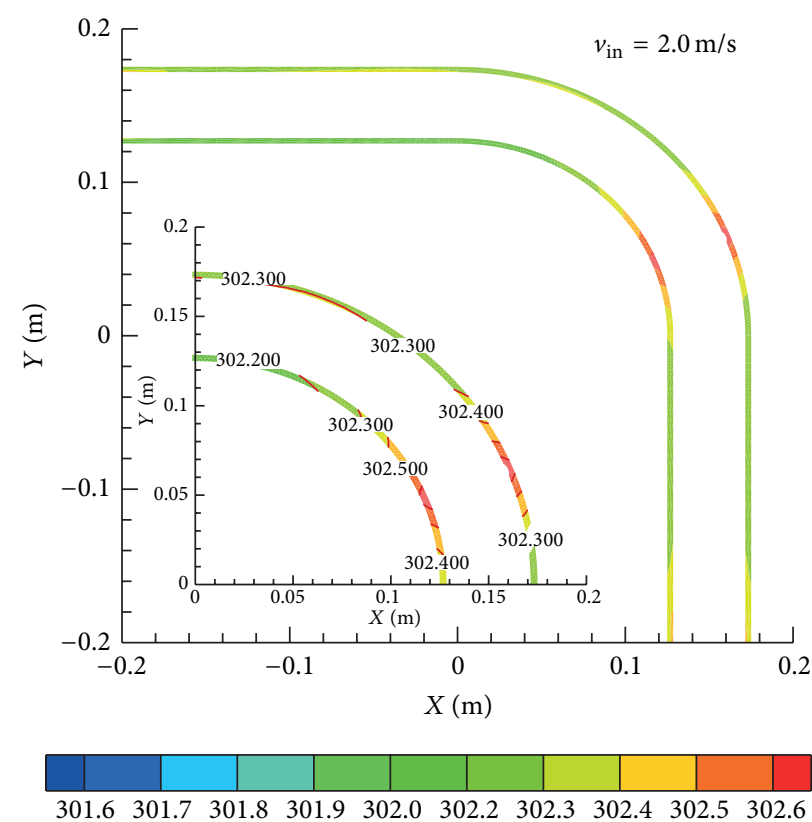

(c)

FIgURE 4: Temperature distribution at the longitudinal cross section of bend pipe at different inlet velocities.

TABLE 2: Simulation cases.

\begin{tabular}{lccc}
\hline Case & Inlet temperature $(\mathrm{K})$ & Inlet rate $(\mathrm{m} / \mathrm{s})$ & Erosion reduced thickness $(\mathrm{mm})$ \\
\hline 1 & 303.15 & 1 & 1 \\
2 & 313.15 & 1 & 1 \\
3 & 323.15 & 1 & 1 \\
4 & 303.15 & 1.5 & 1 \\
5 & 303.15 & 1 & 1 \\
6 & 303.15 & 1 & 0.5 \\
7 & 303.15 & 1 & 1.5 \\
8 & 303.15 & 1 & 2 \\
9 & 303.15 & & 2.5 \\
\hline
\end{tabular}


conducted by changing the inlet temperature while leaving other parameters the same as those in the standard case.

Figure 2 shows the temperature distribution at the longitudinal cross section of bend pipe at different inlet temperatures. To have a better understanding of temperature field in the bend, the contours and values are marked in the partial enlarged view. It is observed that the temperature in the eroded site is higher than that in the surrounding areas. It can be explained that thermal resistance of thin wall is smaller than that of thick wall, leading to more heat transfer through the thin wall. There is also a high temperature zone in the intrados of elbow facing the erosion pit. This is mainly caused by circumferential heat transfer in pipe wall. Another reason for it can be attributed to the secondary flow in cross section. However, the area of high temperature zone in the intrados is smaller than that in the extrados. The higher the inlet temperature, the larger the high temperature zone. And the temperature gradient in pipe wall for high temperature oil flow shows a large value. From the inlet to the outlet of bend section, the temperature in the extrados of bend wall firstly increases and then decreases. But the temperature in the outlet is still smaller than that in the inlet. The temperature drop is $0.178 \mathrm{~K}$ for $T_{\text {in }}$ of $303.15 \mathrm{~K}, 0.089 \mathrm{~K}$ smaller than that for $T_{\text {in }}$ of $313.15 \mathrm{~K}$, and $0.177 \mathrm{~K}$ smaller than that for $T_{\text {in }}$ of $323.15 \mathrm{~K}$.

Figure 3 shows the temperature drop $(\Delta T)$ along the extrados of pipe wall at different inlet temperatures. We can clearly see the temperature affected zone of erosion pit, about $0.52 \mathrm{~m}$ long, which is the same for the three cases. However, the upstream influence distance is not the same as the downstream influence distance. The downstream influence distance is about 2.5 times longer than the upstream influence distance. This is mainly caused by the flowing fluid which is acting as heat carrier. Heat transfer from erosion pit to the upstream is against the flow, making itself more difficult.

The temperature drop curve can be divided into four parts. Temperature drop increases upstream the affected zone, constituting the first part. Temperature drop firstly decreases and then increases in the affected zone, which can be divided into two phases. The obvious reduction in temperature drop upstream the erosion pit describes the second part, while the gradual increase downstream the erosion pit means the third part. The fourth part is the rest one. In the affected zone, temperature drop gradient is large. And the higher the inlet temperature, the larger the temperature drop gradient. The minimum temperature drop presents at the erosion pit. With the decrease in inlet temperature, the minimum temperature drop decreases from $0.998 \mathrm{~K}$ when $T_{\text {in }}=323.15 \mathrm{~K}$ to $0.549 \mathrm{~K}$ when $T_{\text {in }}=303.15 \mathrm{~K}$.

3.2. Effect of Inlet Rate. Economic velocity of oil flow in pipe is $1-2 \mathrm{~m} / \mathrm{s}$. So we selected three common rates $\left(v_{\mathrm{in}}=1 \mathrm{~m} / \mathrm{s}\right.$, $1.5 \mathrm{~m} / \mathrm{s}$, or $2 \mathrm{~m} / \mathrm{s}$ ) to compare the influences on temperature field. The temperature distribution at the longitudinal cross section of bend pipe at different inlet velocities is shown in Figure 4. It can be observed that the faster the oil flow, the smaller the temperature gradient. Comparing the three cases, temperature in the same location either in upstream or

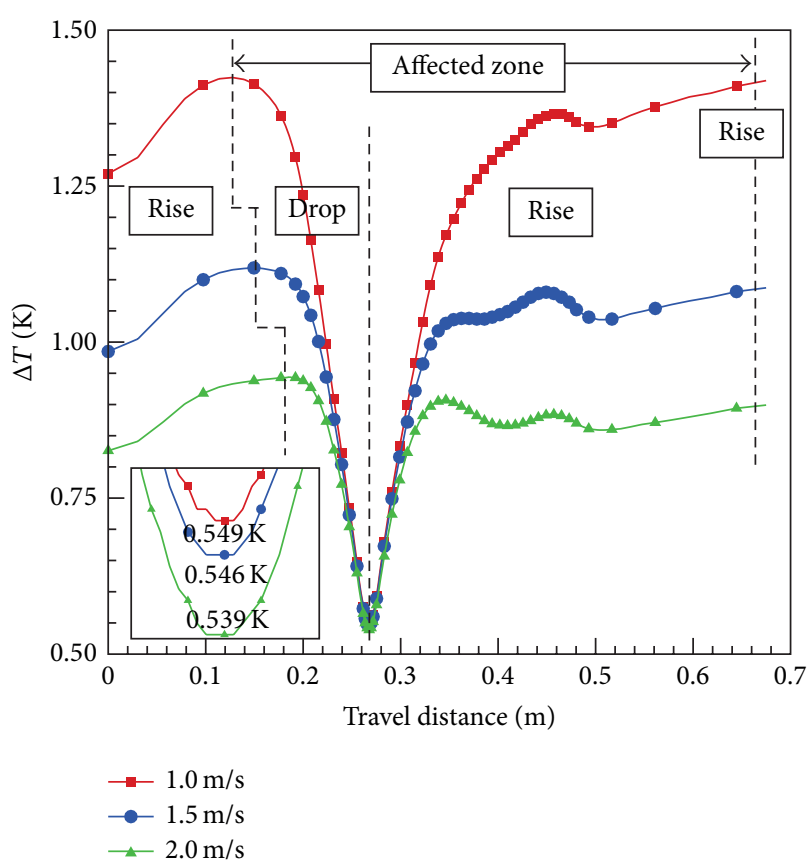

FIGURE 5: Effect of inlet velocity on temperature drop along the extrados of pipe.

downstream the erosion pit is relatively high when $v_{\text {in }}=2 \mathrm{~m} / \mathrm{s}$. It can be explained that a greater amount of fluid is passing through the pipe for fast flow in the same time, providing more heat to exchange with pipe wall.

Figure 5 presents the temperature drop along the extrados of pipe wall at different inlet rates. It is worth noting that the upstream influence distances of affected zone are different in three cases. This distance is $0.138 \mathrm{~m}$ for $v_{\text {in }}=1 \mathrm{~m} / \mathrm{s}$, while it reduces to $0.088 \mathrm{~m}$ for $v_{\text {in }}=2 \mathrm{~m} / \mathrm{s}$. The temperature drop gradient is large in affected zone for slow flow. Relative less heat transfer for slow flow passing through the pipeline could be a major cause for this phenomenon. The minimum temperature drop for $v_{\text {in }}=1 \mathrm{~m} / \mathrm{s}$ is $0.549 \mathrm{~K}$, just $0.003 \mathrm{~K}$ higher than that for $v_{\text {in }}=1.5 \mathrm{~m} / \mathrm{s}$ and $0.01 \mathrm{~K}$ higher than that for $v_{\text {in }}$ $=2 \mathrm{~m} / \mathrm{s}$. In practice, thus, accuracy of the instrument must meet the thousandth if we want to find the difference in temperature.

3.3. Effect of Erosion Reduced Thickness. Effect of erosion reduced thickness $(\Delta r)$ on temperature field is the uppermost concern. As shown in Figure 6, the area of high temperature zone in the vicinity of erosion pit is large for big erosion reduced thickness. As for the small thermal resistance, heat transferring easier in the thin wall is the main reason. In addition, vortex can be formed in large pit. And once vortex happens, fluid would be stagnation and supply heat constantly. Therefore, thin wall in erosion site gets more heat from flowing fluid, and it simultaneously transfers heat in the axial direction and the circumferential direction. That is why the area of high temperature zone is large for deep erosion pit. However, the affected zone of erosion pit is limited. Temperature in the same location a certain distance upstream 

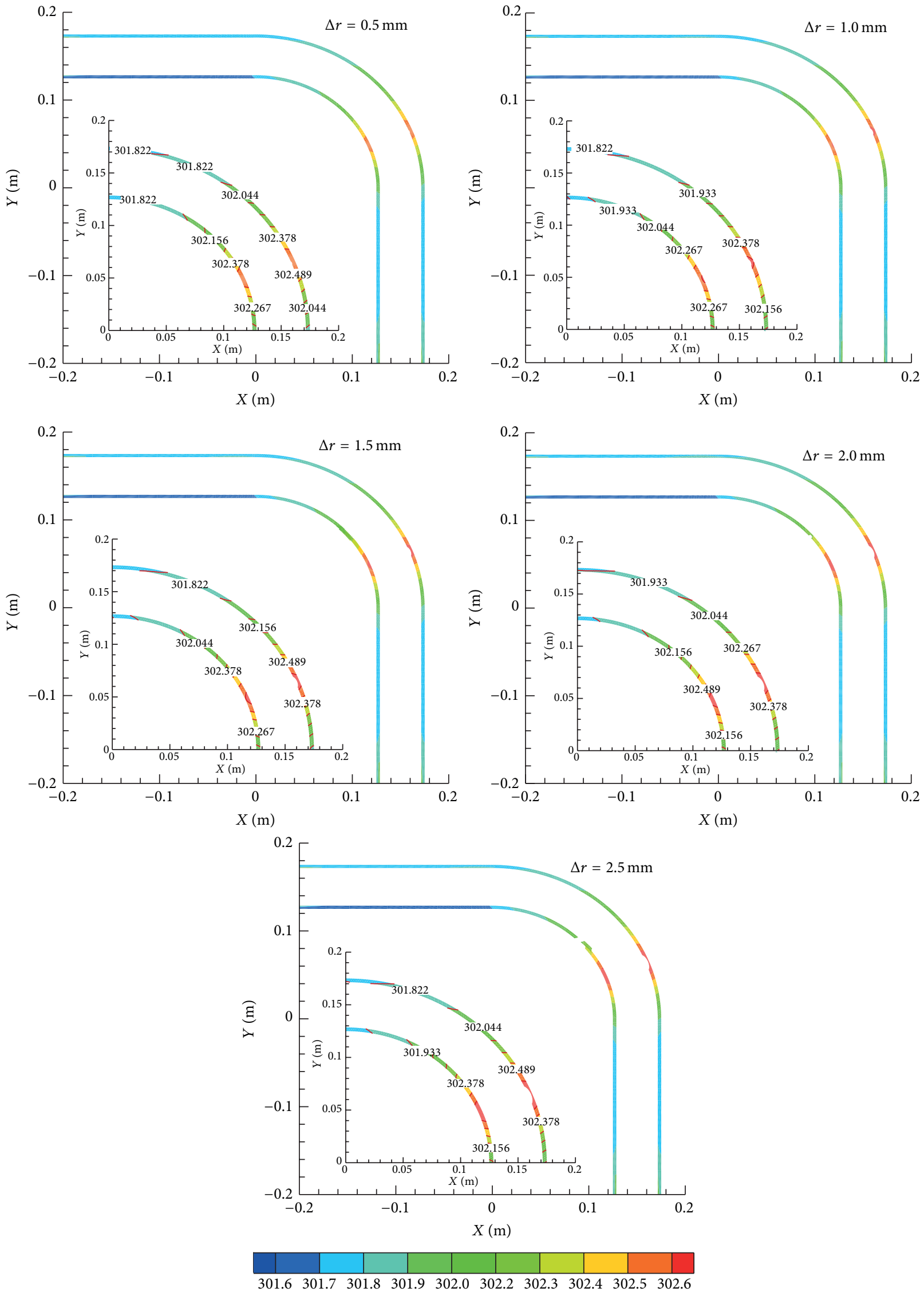

Figure 6: Temperature distribution at the longitudinal cross section of bend pipe at different erosion reduced thicknesses. 
or downstream the erosion pit for the three cases shows the same distribution. It can be also observed from Figure 7.

As shown in Figure 7, the temperature drop curves present the same change trends. The main difference is the minimum temperature drop although the value gap is not great. The minimum temperature drop decreases with the increase of erosion reduced thickness. For $\Delta r=0.5 \mathrm{~mm}$, the minimum temperature drop is $0.593 \mathrm{~K}$, which reduces to $0.46 \mathrm{~K}$ for $\Delta r=2.5 \mathrm{~mm}$.

3.4. Prediction of Erosion Reduced Thickness. Since the minimum temperature drop is closely related to the thickness of pipe wall, the dimensionless minimum temperature drop $\left(\Delta T / T_{\text {in }}\right)$ versus dimensionless erosion reduced thickness $\left(\Delta r / R_{\text {in }}\right)$ is analyzed, and we have obtained the fitting formula, as shown in Figure 8. The fitting line meets the linear distribution well, and the adjust $R^{2}$ is 0.99 . And the fitting formula is written as

$$
1000 \frac{\Delta T}{T_{\text {in }}}=2.04618-0.04553 \frac{100 \Delta r}{R_{\text {in }}}
$$

where $R_{\text {in }}$ is inner radius of pipe.

Using this formula, we can calculate the erosion reduced thickness, if the temperature drop is known in advance. For example, if the actual parameters are the same as those used in this paper such as $T_{\text {in }}=303.15 \mathrm{~K}$ and $R_{\text {in }}=0.0215 \mathrm{~mm}$, this equation can be simplified as

$$
\Delta r=0.00966-0.015577 \Delta T \text {. }
$$

In practice, the outer surface temperature of pipe should be monitored by temperature sensors in order to get the minimum temperature drop. As shown in Figure 9, we can set the temperature sensors around the bend outer wall where presents the high incidence of erosion such as $20-50^{\circ}$ along the extrados of bend. And enough temperature sensors should be arranged, such as five circles and eight sensors per circle as shown in Figure 9.

Using the temperature sensors, we can get the maximum temperature at the outer wall of bend pipe. Simultaneously, the inlet temperature of flow is usually known. So the minimum temperature drop can be obtained. If the minimum temperature drop is $0.6 \mathrm{~K}$, the erosion reduced thickness would be calculated as $0.3138 \mathrm{~mm}$ by substituting $\Delta T$ into the above formula.

Therefore, it may be an easy and fast method to predict erosion reduced thickness, which is only needed to monitor the outer surface temperature of pipe. In order to verify the accuracy of this method, we have conducted the experimental tests under the same conditions with simulations. In the tests, temperature sensors are arranged as shown in Figure 9. Figure 10 depicts the comparison between the experimental results and the calculated value with the formula, which shows a good agreement. Thus, using this way, timely replacement of eroded pipe can be conducted.

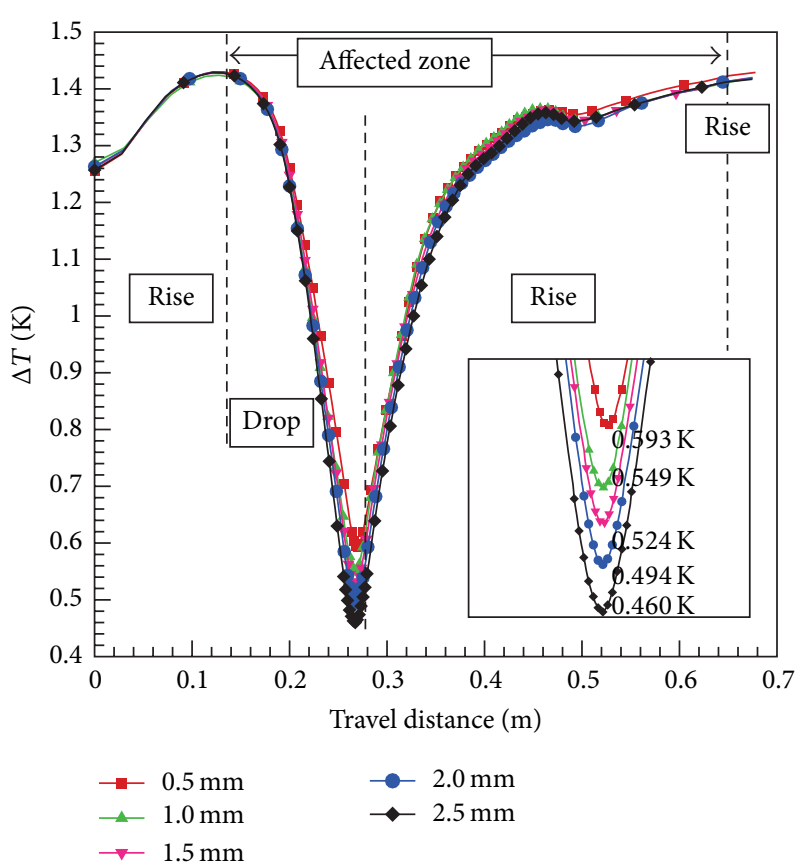

FIGURE 7: Effect of erosion reduced thickness on temperature drop along the extrados of pipe.

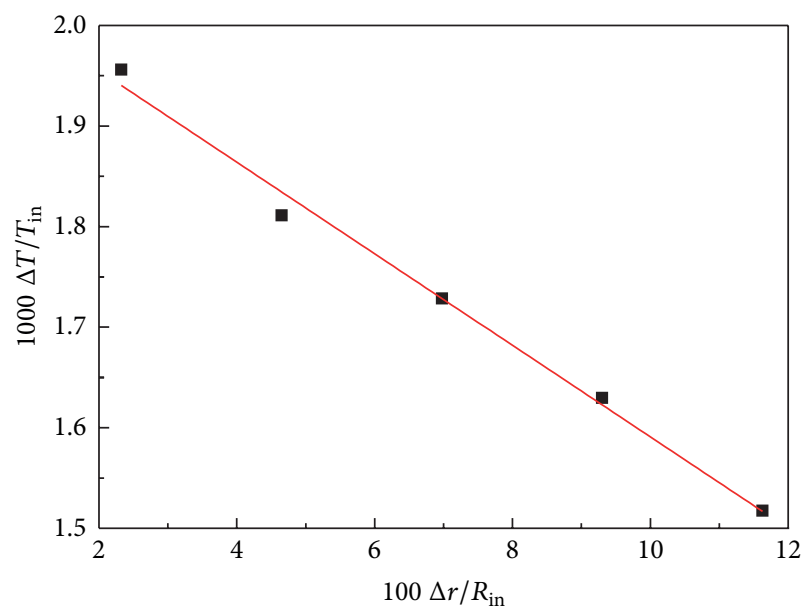

\begin{tabular}{|l|l|l|l|}
\hline Equation & $y=a+b * x$ & & \\
\hline Weight & No weighting & & \\
\hline $\begin{array}{l}\text { Residual sum of } \\
\text { squares }\end{array}$ & $8.47661 E-4$ & & \\
\hline Pearson's $r$ & -0.99624 & & \\
\hline Adj. $R^{2}$ & 0.99 & & \\
\hline & & Value & Standard error \\
\hline$a$ & Intercept & 2.04618 & 0.01763 \\
\hline$b$ & Slope & -0.04553 & 0.00229 \\
\hline
\end{tabular}

Simulation results Fitting line

Figure 8: The dimensionless minimum temperature drop $\left(\Delta T / T_{\text {in }}\right)$ versus dimensionless erosion reduced thickness $\left(\Delta r / R_{\mathrm{in}}\right)$. 


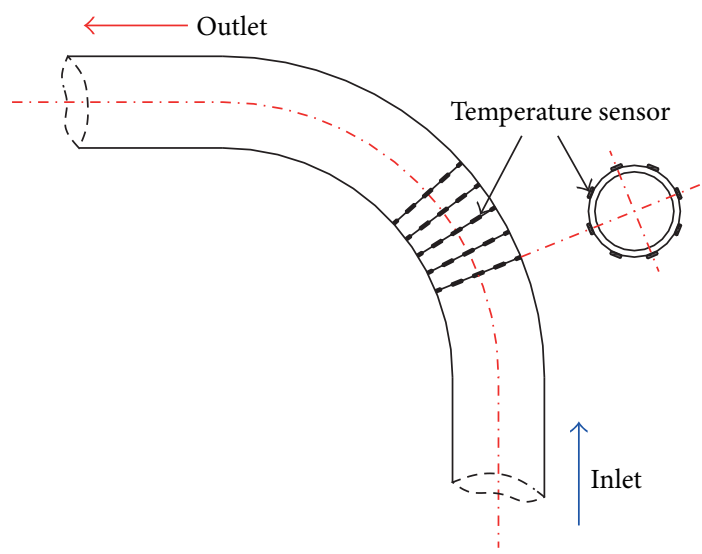

FIGURE 9: Schematic diagram of the temperature monitoring arrangement.

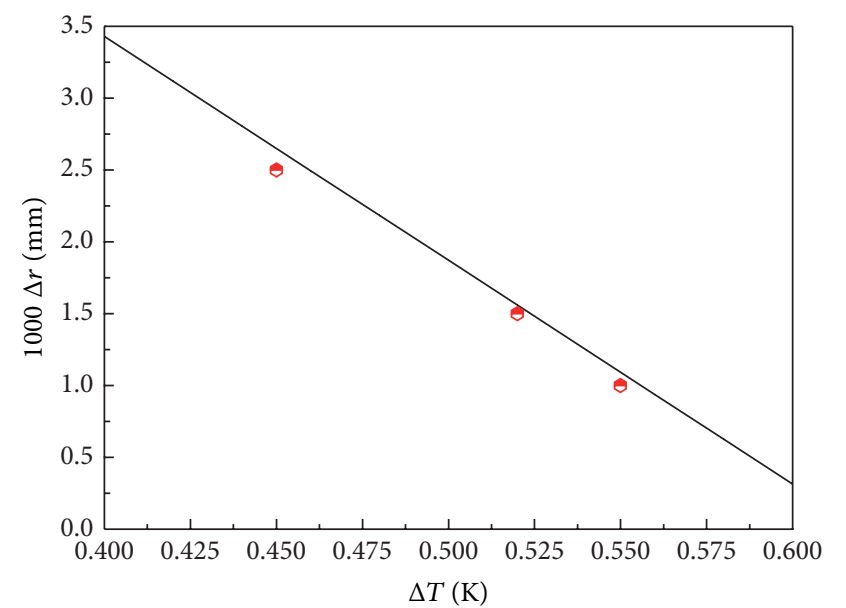

- Calculated results

- Measured results

FIGURE 10: Comparing between the experimental results and the calculated value.

\section{Conclusions}

A numerical simulation of temperature distribution in an eroded bend pipe was carried out focusing on the investigation into predicting the erosion reduced thickness in elbow. By conducting a series of simulations, effects of oil inlet rate, oil inlet temperature, and erosion reduced thickness on temperature distribution in elbow are examined. Then the dimensionless minimum temperature drop is analyzed and the fitting formula is obtained. Finally, a new method for predicting erosion reduced thickness in bend pipe is proposed, which can provide useful guidance for pipeline monitoring and replacement. According to the results of the analysis, the following conclusions can be drawn.

(1) Temperature in the eroded site is high due to the small thermal resistance. And the presence of erosion pit affects the temperature distribution in pipe wall significantly. Temperature drop curve along the extrados of pipe can be divided into four parts. In the affected zone, temperature drop firstly decreases and then increases.

(2) Small inlet temperature or large inlet velocity can lead to small temperature drop, while shallow erosion pit causes great temperature drop.

(3) The fitting formula of the dimensionless minimum temperature drop versus dimensionless erosion reduced thickness is obtained. After the outer surface temperature of bend pipe is obtained by monitors, we can calculate the erosion reduced thickness by using the formula. And the accuracy has been verified by experimental tests. It provides a new method for pipe engineers to predict the service life of pipe and conduct replacement process.

\section{Conflict of Interests}

The authors declare that there is no conflict of interests regarding the publication of this paper.

\section{Acknowledgments}

This research work was supported by Open Fund (no. PLN1210) of State Key Laboratory of Oil and Gas Reservoir Geology and Exploitation (Southwest Petroleum University), Key Project of Sichuan Provincial Education Department (no. 12ZA189), and the special fund of China's Central Government for the Development of Local Colleges and Universities - the project of National First-Level Discipline in Oil and Gas Engineering (no. P019). Without the support, this work would not have been possible.

\section{References}

[1] Q. H. Mazumder, S. A. Shirazi, and B. McLaury, "Experimental investigation of the location of maximum erosive wear damage in elbows," Journal of Pressure Vessel Technology, vol. 130, no. 1, Article ID 011303, 7 pages, 2008.

[2] H. Zhang, Y. Q. Tan, D. M. Yang et al., "Numerical investigation of the location of maximum erosive wear damage in elbow: effect of slurry velocity, bend orientation and angle of elbow," Powder Technology, vol. 217, pp. 467-476, 2012.

[3] J. Postlethwaite and U. Lotz, "Mass transfer at erosion-corrosion roughened surfaces," The Canadian Journal of Chemical Engineering, vol. 66, no. 1, pp. 75-78, 1988.

[4] Y. Q. Tan, H. Zhang, D. M. Yang, S. Q. Jiang, J. H. Song, and Y. Sheng, "Numerical simulation of concrete pumping process and investigation of wear mechanism of the piping wall," Tribology International, vol. 46, pp. 137-144, 2012.

[5] J. R. Fan, K. Luo, X. Y. Zhang, and K. C. Cen, "Large eddy simulation of the anti-erosion characteristics of the ribbedbend in gas-solid flows," Journal of Engineering for Gas Turbines and Power, Transactions of the ASME, vol. 126, no. 3, pp. 672679, 2004.

[6] R. Li, A. Yamaguchi, and H. Ninokata, "Computational fluid dynamics study of liquid droplet impingement erosion in the inner wall of a bent pipe," Journal of Power \& Energy Systems, vol. 4, no. 2, pp. 327-336, 2010. 
[7] D. Castiñeira and T. F. Edgar, "CFD for simulation of steamassisted and air-assisted flare combustion systems," Energy \& Fuels, vol. 20, no. 3, pp. 1044-1056, 2006.

[8] H. J. Zhu, X. L. Yang, J. J. Li, and N. Li, "Simulation analysis of thermal influential factors on crude oil temperature when double pipelines are laid in one ditch," Advances in Engineering Software, vol. 65, pp. 23-31, 2013.

[9] S. V. Patankar, Numerical Heat Transfer and Fluid Flow, McGraw-Hill, New York, NY, USA, 1980.

[10] Y. M. Ferng, "Predicting local distributions of erosion-corrosion wear sites for the piping in the nuclear power plant using CFD models," Annals of Nuclear Energy, vol. 35, no. 2, pp. 304313, 2008.

[11] P. Tang, J. Yang, J. Y. Zheng et al., "Failure analysis and prediction of pipes due to the interaction between multiphase flow and structure," Engineering Failure Analysis, vol. 16, no. 5, pp. 1749-1756, 2009. 

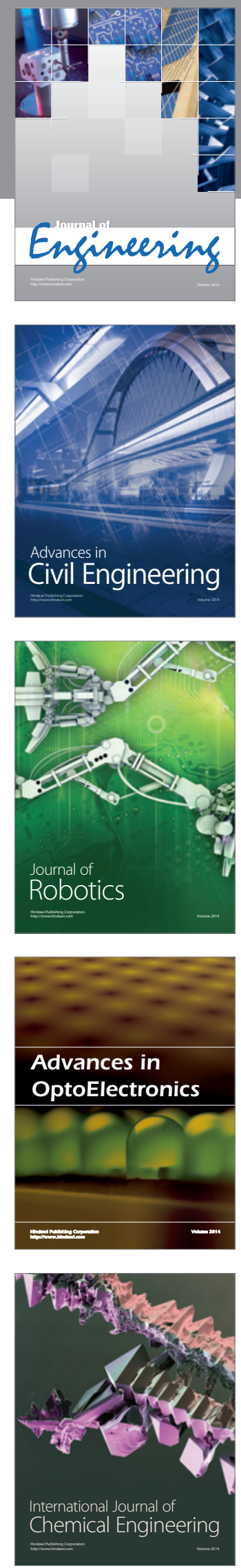

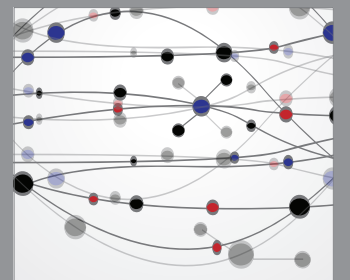

The Scientific World Journal
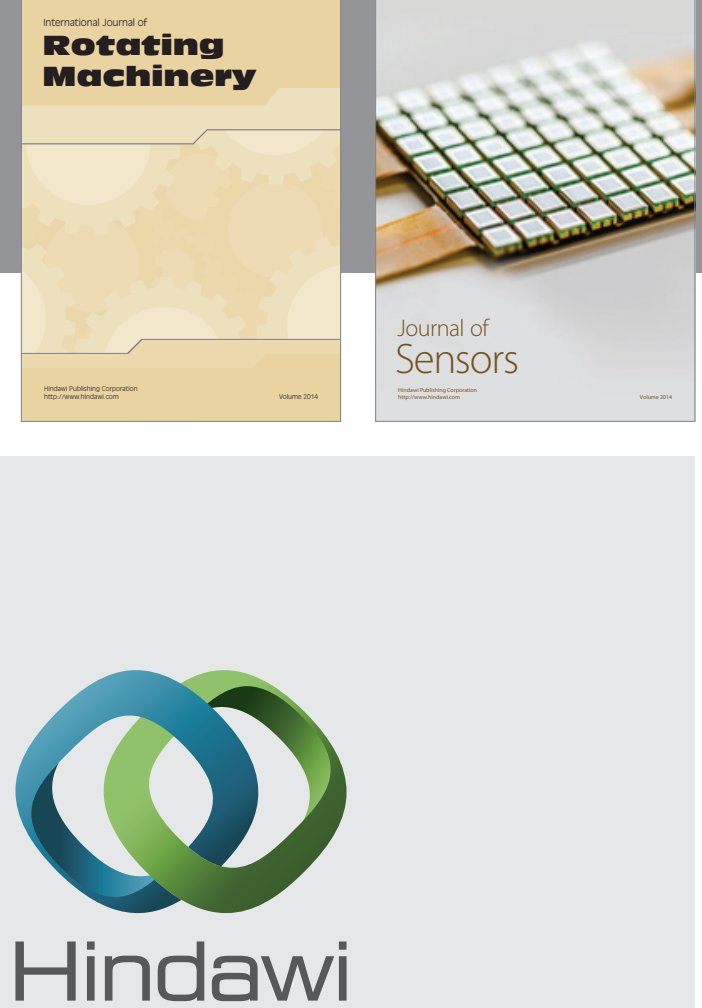

Submit your manuscripts at http://www.hindawi.com
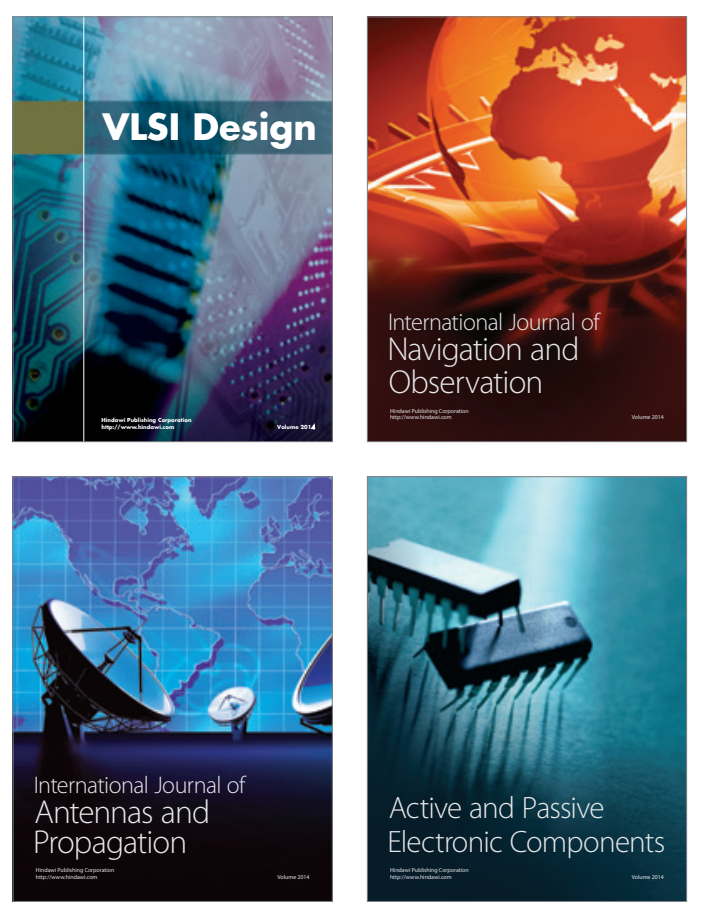
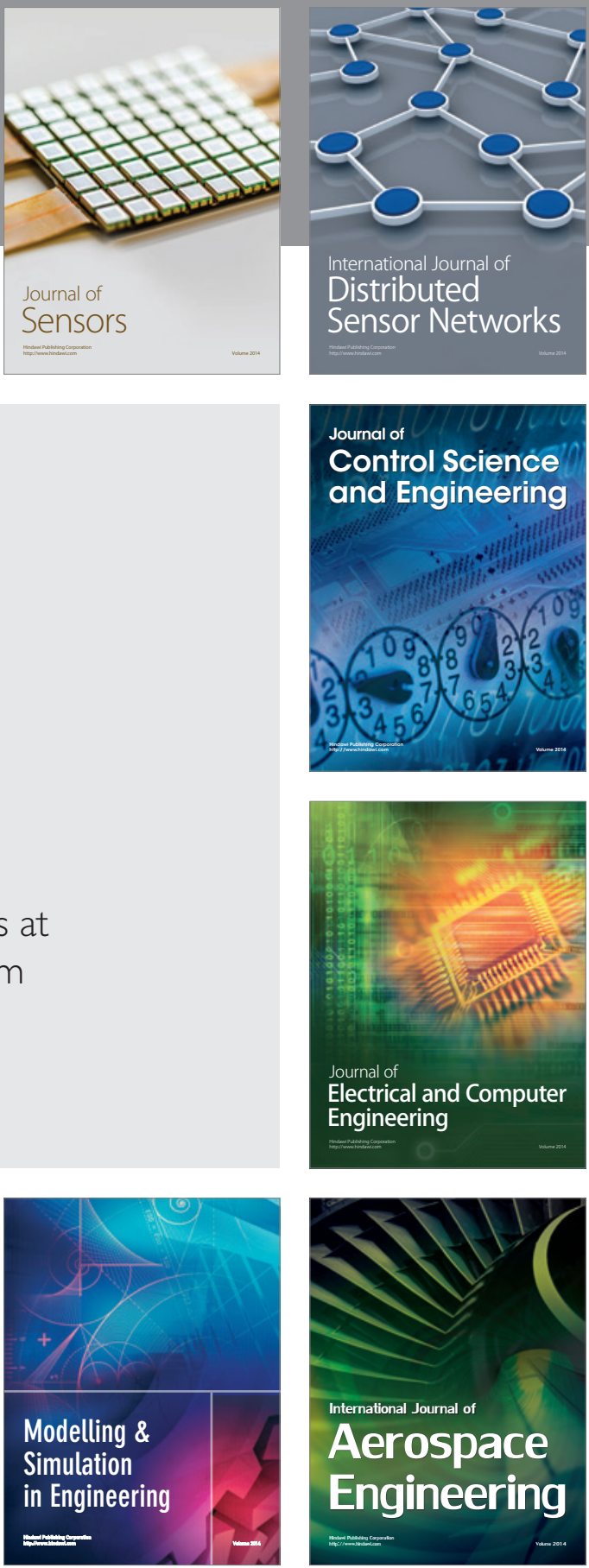

Journal of

Control Science

and Engineering
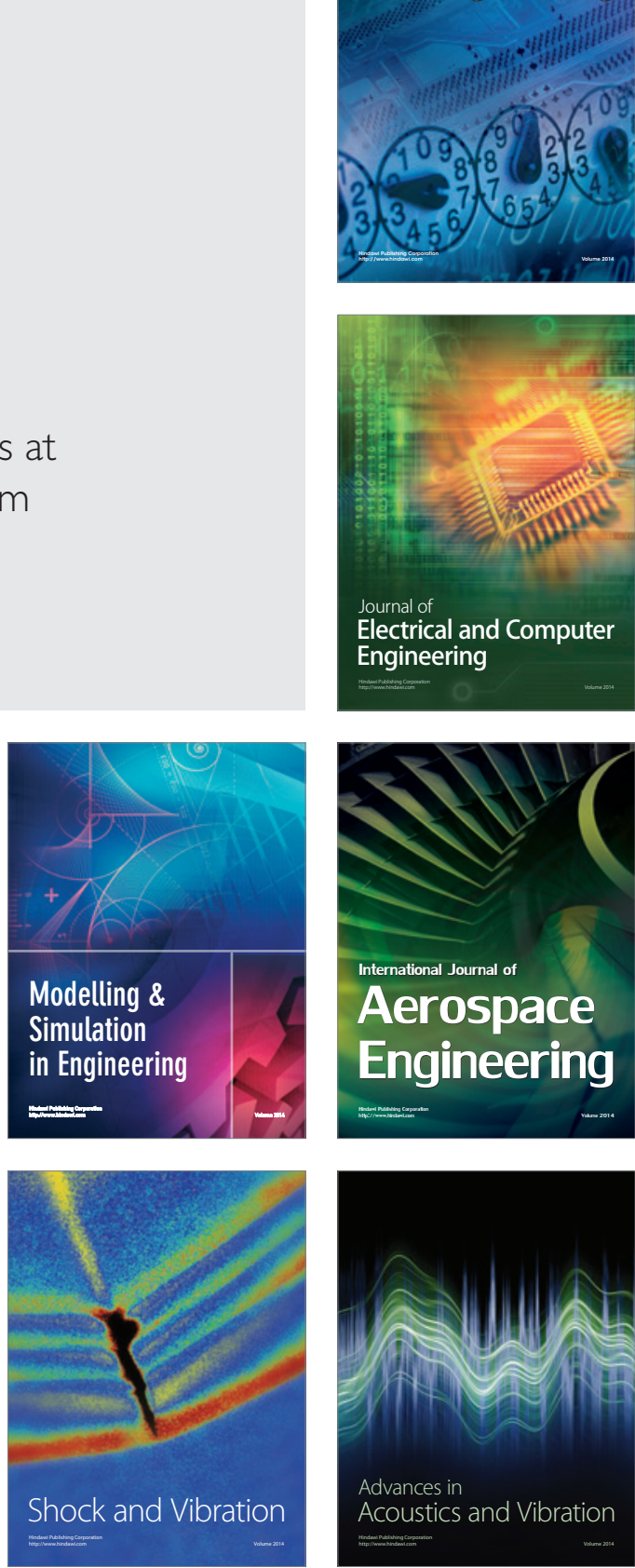